\title{
Overweight Risk and Parental Concerns of Risk for Chinese Preschoolers in the U.S., China and Taiwan
}

\author{
Jyu-Lin Chen ${ }^{1}$, Jingxiong Jiang ${ }^{2}$, and Ruey-Hsia Wang ${ }^{3}$ \\ ${ }^{1}$ University of California San Francisco \\ ${ }^{2}$ National Center for Women's and Children's Health, China CDC \\ ${ }^{3}$ Kaohsiung Medical University, School of Nursing
}

\begin{abstract}
Background and Purpose: The World Health Organization (WHO) has designated childhood obesity as a global epidemic. Parental factors such as perceptions of their child's weight status, concerns about their child's weight, parental feeding practices, and parents' own weight status may be associated with increased obesity risk among preschool children. This study aims to explore factors related to body mass index (BMI) and parental concerns about their children's weight among Chinese pre-school aged children in the U.S., China and Taiwan. Methods: A cross-sectional study design was utilized. One hundred children (ages 3-5) and their parents participated in the study. Parents completed a family eating and activity habit questionnaire, a child feeding practices survey, a child bdy shape pictorial list, and a demographic survey. Children had their weight and height measured. Results: Fathers' elevated BMI was related to higher children's BMI $\left(\mathrm{R}^{2}=.095, \mathrm{p}=005\right)$, especially among boys. Parent-reported food restriction practices, perception of their child being heavy, increased food monitoring, and higher children's activity level were associated with increased concerns for a child's weight $\left(R^{2}=.43, p=001\right)$. Conclusion: In contrast to literature that focuses on mothers, our study suggests that obesity prevention for Chinese fathers may assist in the obesity prevention efforts of their young children, especially among boys. In addition, parent education on healthy feeding practices for preschool children is warranted for preventing childhood obesity.
\end{abstract}

(C) 2014 Californian Journal of Health Promotion. All rights reserved.

Keywords: Childhood obesity, parental concerns, Chinese, preschool

\section{Introduction}

Childhood obesity is a global epidemic, and is growing in many developing countries including Mainland China and Taiwan. The prevalence of overweight and obesity among Chinese children was $21 \%$ in China, $27 \%$ in Taiwan, and $25 \%$ in the U.S. in 2009 (Au, Kwong, Chou, Tso, \& Wong, 2009). Family environment (such as availability of unhealthy foods and access to physical activity facilities) is a key influence on the development of children's food preferences, eating styles and activity patterns; furthermore parental overweight and obesity is also an important predictor for obesity in their children (Birch \& Davison, 2001; Bruss, Morris, \& Dannison, 2003; Fisher, Mitchell, SmiciklasWright, \& Birch, 2002; Kral \& Rauh, 2010).
Parental perceptions of their child's weight status may determine whether the family will take any action to improve the healthy lifestyle behaviors needed to prevent their child from experiencing excessive weight gain. The findings of a systematic literature review in preschool-age children of all ethnicities found that parental misperception of their child's weight is common and as much as $62.4 \%$ of overweight and/or obese children were perceived as having a normal weight by their parents. Furthermore parents not recognizing their children's overweight status is higher with children aged 2-6 years compared to older children (Liu, 2009), and is even higher for Chinese and Chinese-American school-aged 
children (Chen, \& Wu, 2008; Chen, Kennedy, Yeh, \& Kools, 2005).

Studies have found that concerned parents use specific child-feeding strategies, such as increased food intake monitoring and limited access to unhealthy food, in an attempt to decrease their child's weight (Kasemsup \& Reicks, 2006; May et al., 2007; Zhang \& McIntosh, 2011). Studies have found that parental feeding practices were associated with childhood obesity in the United States, especially the parental restriction of certain foods (such as sweets) and the use of food as a reward (Kroller \& Warschburger, 2008; Rollins, Loken, Savage, \& Birch, 2014). Such findings have been replicated in Chinese preschool-aged children in China (Morrissey, Dunifon, \& Kalil, 2011). However, one study of Chinese American parents found no association between parental feeding practices and children's weight (Huang et al., 2012), and no known study has examined this association among Taiwanese children.

\section{The Current Study}

Chinese Americans are the largest and fastest growing Asian subgroup in the United States (Bureau, 2009). Many of the Chinese immigrants in the U.S. are from Mainland China and Taiwan. Though Chinese people may share similar cultural beliefs and values, such as the concepts of yin and yang, the importance of family, parents' child feeding practices as well as perceptions of healthy weight for young children may differ depending on the environment (i.e., availability of food and physical activity facilities). For instance, there may be more affordable access to fresh vegetables and fruits in Asian countries relative to the U.S., while there may be more access to recreational facilities and parks in the U.S. compared to Asian countries. Thus, research on factors associated with obesity and parental concern on child's weight in young Chinese children is warranted. Understanding similarities and differences in risk factors in these countries can assist clinicians and researchers in designing effective interventions to reduce childhood obesity prevalence. Thus, this study aimed to explore risk factors in childhood obesity and parental concern about their child's weight in young Chinese children in Mainland China, Taiwan and the U.S.

\section{Methods}

\section{Sample}

A cross-sectional study design was used. The University of California, San Francisco Committee on Human Research and local school authorities in Taiwan and Mainland China approved this study. Inclusion criteria were children between ages three and five years attending regular preschool, whose parents identified themselves as Chinese. In addition, parents of these children had to be able to read and write Chinese (either in Mandarin or Cantonese) in China and Taiwan, and to be able to read and write Chinese (either in Mandarin or Cantonese) and English in the U.S.

\section{Data Collection}

Participants were recruited through six local preschools in these countries (two local preschools from each country). These preschools were selected because of the authors' experience of working with them. Since this is one of the first international collaborations conducted to explore Chinese parental concerns related to young children's weight in Mainland China, Taiwan and the U.S., we also aimed to test the feasibility of conducting this type of work in the three countries. Therefore, sample sizes in this study were small.

A brief presentation of the study was given at parent information sessions at the local preschools. The research assistant gave parents who were interested in the study a letter of introduction to the study and an informed consent form to take home. Parents who were interested in having their child participate in the study signed and returned the consent form to the research assistant within one week of receiving it, providing their names and contact information to the research team. A follow up meeting was scheduled with parents and the child to assess eligibility as noted in the previous paragraph. A total of 100 children and their parents completed the assessments in the study $($ U.S. $=28$, China $=47$, Taiwan $=25)$. 
Trained research assistants measured each child's weight and height. Parents completed a family eating and activity habit questionnaire, a child feeding practices survey, a child body shape pictorial list, and a demographic survey. All questionnaires were translated into Mandarin or Cantonese Chinese and translated back into
English to ensure linguistic equivalence. These questionnaires were completed at home and returned in sealed envelopes to the preschool within two weeks of recruitment into the study. Each family received the equivalent of US $\$ 10$ as an incentive for completing the surveys.

Table 1.

Descriptive Statistics by Country

\begin{tabular}{|c|c|c|c|}
\hline Variables & $\begin{array}{l}\text { Mainland China } \\
\quad(\mathrm{N}=47)\end{array}$ & $\begin{array}{l}\text { Taiwan } \\
(\mathrm{N}=25)\end{array}$ & $\begin{array}{c}\text { U.S. } \\
(\mathrm{N}=28)\end{array}$ \\
\hline \multicolumn{4}{|l|}{ Child characteristics } \\
\hline Child BMI & $16.63(3.58)$ & $16.67(2.76)$ & $15.43(1.57)$ \\
\hline Overweight or obesity prevalence (\%) & $12.8 \%$ & $36 \%$ & $16 \%$ \\
\hline Child age (years) & $4.1(1.1)$ & $4.9(0.6)$ & $4.57(0.84)$ \\
\hline \multicolumn{4}{|l|}{ Family eating/activity habits } \\
\hline *Child activity hours/week ${ }^{2,3}$ & $3.32(.86)$ & $4.5(3.4)$ & $5.1(3.43)$ \\
\hline *TV/computer time ${ }^{1,2}$ & $5.7(1.58)$ & $8.9(7.96)$ & $3.95(3.95)$ \\
\hline *Stimulus exposure ${ }^{1,2,3}$ & $17.69(1.78)$ & $15.61(2.69)$ & 14.33 (3.79) \\
\hline${ }^{*}$ Eating related to hunger-Child ${ }^{1,2,3}$ & $12.40(1.21)$ & $11.12(1.69)$ & $8.48(1.74)$ \\
\hline *Eating style-Child ${ }^{1,2,3}$ & $36.74(2.54)$ & $38.40(7.28)$ & $32.2(7.32)$ \\
\hline \multicolumn{4}{|l|}{ Child feeding practice } \\
\hline Perceived obesity status of child & $2.99(.54)$ & $2.93(.57)$ & $2.70(.64)$ \\
\hline${ }^{*}$ Concern about child's weight ${ }^{1,2}$ & $1.97(.87)$ & $3.01(.76)$ & $2.31(1.16)$ \\
\hline *Perceived responsibility of food intake, ${ }^{3}$ ? & $3.74(.87)$ & $3.26(.91)$ & $4.25(.70)$ \\
\hline *Pressure to eat ${ }^{1,3}$ & $2.60(.58)$ & $3.53(.86)$ & $3.34(.78)$ \\
\hline *Restriction of food intake ${ }^{1,3}$ & $2.90(.51)$ & $4.06(.44)$ & $3.66(.76)$ \\
\hline *Monitoring of food intake ${ }^{1,3}$ & $1.81(.85)$ & $3.31(.95)$ & $4.0(1.11)$ \\
\hline \multicolumn{4}{|l|}{ Body dissatisfaction } \\
\hline Parent's body dissatisfaction of son & $-.26(.93)$ & $.53(1.25)$ & $.21(.97)$ \\
\hline $\begin{array}{l}\text { Parent's body dissatisfaction of } \\
\text { 1,3 daughter* }\end{array}$ & $-.50(.84)$ & $.44(.88)$ & .33 (.89) \\
\hline
\end{tabular}

\section{Measures}

Family Information. Parents completed a 12item questionnaire that asked about parent(s)' and children's ages, parents' weights and heights, parents' occupation(s), family income, and parents' levels of education.

Children's BMI. BMI was calculated by dividing body mass in kilograms by height in meters squared $\left(\mathrm{kg} / \mathrm{m}^{2}\right)$ (Freedman, 2000). The BMI cutoff established by the International Obesity Task Force (IOTF) was used to classify children's weight status. The international cut off points for BMI for overweight and obesity by gender between 2 and 18 years was developed to reflect the widely used cut off points of 25 and $30 \mathrm{~kg} / \mathrm{m}^{2}$ for adult overweight and obesity (Cole, Bellizzi, Flegal, \& Dietz, 2000). Data was used from six countries (Brazil, Great Britain, Hong Kong, Netherlands, Singapore, and the US) to model the curves used for international studies.

Family Eating and Activity Habit Questionnaire (FEAHQ). The FEAHQ was used to monitor the environmental factors and family behaviors associated with children's 
weight (Golan \& Weizman, 1998). It has four subscales: the activity level subscale (4 items) that measures the frequency with which the parent, spouse, and child engage in physical activity (such as biking and swimming) and sedentary activity (such as watching TV); the stimulus exposure subscale (8 items) that measures presence and visibility of snacks, sweets, cakes, and ice cream in the home, and the child's autonomy in buying or taking these foods; the eating related to hunger subscale (4 items) that measures whether the person's eating is due to hunger or other states such as boredom or anxiety; and the eating styles subscale (13 items) that measures whether parent, spouse, or child eats while standing in front of the open refrigerator, while watching TV or doing homework, when experiencing stress or between meals. The FEAHQ has established content validity and internal consistency reliability (Golan \& Weizman, 1998). The internal consistency reliability ranged from .78 to .88 .

Child Feeding Questionnaire (CFQ). The CFQ contains 31 items which measure seven different dimensions: perceived parent weight, perceived child weight, parental concern about child's weight, parental responsibility of preparing healthy food, use of restriction for food intake, pressuring children to eat more, and the monitoring of children's food intake. The CFQ has an adequate content validity and internal consistency reliability (Boles et al., 2010). The internal consistency reliability ranged from .70 to .92 .

Child Body Shape Pictorial List. Parents were asked to use a pictorial instrument to make two figure selections to assess the child's current figure and the child's ideal figure (Rich et al., 2008). Each response was scored on a 7-point scale, with 1 representing the thinnest figure and 7 representing the largest figure. The scale was not visible to the participants. Body image dissatisfaction was determined by subtracting the current figure from the ideal figure. A positive number represents the desire to be thinner (current - ideal $>0$ ), while a negative number represents a desire to be larger (current - ideal $<0$ ). Possible score ranges from -7 to +7 .

\section{Statistical Analyses}

Appropriate descriptive statistics, means, and standard deviations for the quantitative variables, as well as frequencies and percentages for categorical variables, were calculated for all of the study variables. Oneway analysis of variance (ANOVA) was used to detect any difference in continuous variables among the three countries. Linear regressions were performed on variables regarding children's BMI and parental concerns. Predictors entered to regression models included country, child's age, gender, maternal BMI, paternal BMI, body image score, all subscales from FEAHQ and CFQ. All statistical analyses were performed using SPSS version 20 for Windows.

\section{Results}

A total of 100 children (ages 3-5) and their families participated in the study (U.S. $=28$, China $=47$, Taiwan $=25$ ). The mean age of the children was $4.43(\mathrm{SD}=1.05)$ and $\mathrm{BMI}$ was 16.23 ( $\mathrm{SD}=3.08$ ). About $49 \%$ of the children were boys. Approximately $15.1 \%$ of children were overweight and $3.1 \%$ were obese based on the cut off established by IOTF. No difference was found in children's age, BMI, weight status, and gender distribution among the three countries $(p>.05)$. No difference was found in all variables between boys and girls. However, mothers and fathers in the U.S. were significantly older and more educated than mothers and fathers in Mainland China and Taiwan. No difference was found in parental BMI among countries.

Significant differences were found in family eating and activity subscales and child feeding practices, except for the parents' perception of their child's weight and the body dissatisfaction of the parents of the boys, among the three countries (See Table 1). For example, parents in Mainland China reported a desire for a larger body size for girls, whereas parents in Taiwan and U.S. preferred a smaller body size for girls. Parents in Taiwan also reported higher levels of concern about their child's weight than parents in Mainland China and U.S.

Among overweight and/or obese children, only $31.3 \%$ of parents perceived their children as 
overweight $(n=5)$. Concerns about a child's weight were not related to perceived child's weight but body dissatisfaction $\left(\mathrm{R}^{2}=.34, \mathrm{p}=\right.$ .001). Preference for smaller body size was related to increased concern about child's weight $\left(\mathrm{R}^{2}=.13, \mathrm{p}=01\right)$ when controlling for age, gender, BMI, and country (Taiwan, China and US). Linear regression models found that increased food restriction practice, perceived child's weight, food monitoring, and child's activity level contributed to increased concerns of children's weight $\left(\mathrm{R}^{2}=.59, \mathrm{p}=001\right)$ (Table 2).

Table 2.

Stepwise Multiple Regression Summary Table for Parental Concern about Child's Weight

\begin{tabular}{lcccc}
\hline \multicolumn{1}{c}{ Gender/Variable } & $\mathrm{R}^{2}$ & Beta & $\mathrm{p}$ & $\mathrm{sr}^{2}$ \\
\hline Overall & .43 & & .0001 & \\
Increased food restriction & & .38 & .013 & .08 \\
Perceived child as overweight & & .46 & .004 & .11 \\
Increased food monitoring & .28 & .002 & .13 \\
Increased child activity level & & .03 & .014 & .09 \\
\hline
\end{tabular}

Linear regression indicated that a father's elevated BMI was related to higher BMI in all children $\left(\mathrm{R}^{2}=.09, \mathrm{p}=006\right)$ (Table 3$)$. When we analyzed data by child's gender, increased BMI in fathers was associated with increased BMI in boys $\left(\mathrm{R}^{2}=.12, \mathrm{p}=03\right)$. No factor was found to relate to increased $\mathrm{BMI}$ in girls.

Table 3.

Regression of Child's BMI

\begin{tabular}{lcccccc}
\hline Gender/Variable & $\mathrm{R}^{2}$ & Beta & $\mathrm{df}$ & $\mathrm{t}$ & $\mathrm{p}$ & $\mathrm{sr}^{2}$ \\
\hline Overall & .09 & & 1,82 & 2.73 & .006 & \\
Father's BMI & & .35 & & 2.73 & .006 & .09 \\
\hline
\end{tabular}

\section{Discussion}

This study found significant differences among preschoolers from Taiwan, China, and the U.S. related to parent-reported eating and physical activity behaviors, as well as parental feeding practices. A father's increased BMI was related to their children's BMI, especially for boys. In our study, less than one third of parents of overweight and/or obese preschool age children perceived their children to be overweight. When concerned about their child's weight, parents tended to increase food restriction practices on their children, and engaged in more food monitoring. Based on the literature, increased restriction and monitoring of children's food intake increases the likelihood of children consuming unhealthy foods, as children may lack the ability to self-regulate their food intake, and they also tend to overeat unhealthy foods when they have access to them (Hennessy, Hughes, Goldberg, Hyatt, \& Economos, 2012; McGowan, Croker, Wardle, \& Cooke, 2012).

Although parents from the three countries share the same culture of origin, their current living environment might impact some of their behaviors such as physical activity and food intake. These differences may be due to environmental factors which are related to the accessibility of food and physical activity. Research has demonstrated that access to neighborhood recreational facilities increases physical activity (De Meester, Van Dyck, De Bourdeaudhuij, \& Cardon, 2014; Willenberg et al., 2010) and increased availability of healthy food is associated with consuming healthy foods (Oreskovic, Winickoff, Kuhlthau, Romm, \& Perrin, 2009; Sturm \& Datar, 2005). It is important for clinicians and researchers to be aware of these differences when designing interventions.

Our study findings are similar to other studies which suggest that father's BMI is an important factor in obesity among children (Freeman et al.., 2012; (Xu, Dubois, Burnier, Girard, \& Prud'homme, 2011). Data from the Quebec Longitudinal Study of Child Development found that boys with overweight and/or obese fathers were twice as likely to be overweight and/or obese compared to boys with normal weight fathers. Given the high prevalence of obesity among Chinese fathers (64\% of fathers were either overweight and/or obese in this study), programs to reduce BMI in overweight and obese fathers are needed. Studies have found that interventions targeting overweight parents can not only reduce parents' weight, but also the 
overweight status of their children (Boutelle, Cafri, \& Crow, 2011, 2012; Wrotniak, Epstein, Paluch, \& Roemmich, 2004).

Although parents in these three countries reported similar perceptions regarding their child's weight status, less than $32 \%$ of parents of overweight/obese children perceived their children as overweight. Our results are similar to another study, which indicated that overweight and obese children were perceived as normal weight by their parents (Chen, \& $\mathrm{Wu}, 2008$ ). Parents who do not believe their children are overweight or are not concerned about their child's weight may not initiate preventive obesity actions such as increased physical activity and a balanced diet (Crawford, Timperio, Telford, \& Salmon, 2006; Karp el al, 2014). Future studies should examine factors (such as perception of healthy weight, cultural norms on appropriate body shape) that influence parental beliefs regarding children's weight status, specifically in families of overweight children.

Our study findings indicate parents use unhealthy feeding practices (such as increased food restriction and monitoring) when they are concerned about their children's weight. Our finding is supported by another study (Chia, 2008). Since unhealthy child-feeding practices increases childhood obesity risk and unhealthy eating behaviors, programs that teach appropriate child-feeding practice may decrease these risks. Clinicians and researchers should also assess the level of parental concerns regarding their child's weight as over-concerned parents tend to practice unhealthy feeding practices which increase the risk for childhood obesity.

\section{Limitations}

This study utilized a cross-sectional study design with a small sample size and convenience sampling. Future studies would have wider applicability if they include larger samples and use longitudinal designs to examine and determine temporal relationships between predictor variables (such parental weight status, parental feeding practices, environmental factors) and outcomes of interest (child's BMI and parental concerns about their child's weight)

\section{Conclusion}

As the world experiences increases in transmigration, health care providers are working with patients from increasingly diverse ethnic and cultural backgrounds ( $\mathrm{Au}$ et al., 2009). Limited research in the U.S. that has evaluated culturally tailored childhood obesity prevention programs specific to certain ethnic groups (such as Latinos and African Americans) have found some success. (Fitzgibbon et al., 2005, 2006; Fitzgibbon et al., 2010; HarveyBerino \& Rourke, 2003) Therefore, understanding factors associated with overweight risk in Chinese preschoolers can help healthcare providers and researchers to develop culturally appropriate and more efficient programs to promote positive health behaviors and prevent obesity.

\section{Acknowledgements}

This study was made possible by funding from the University of California Pacific Rim Research Program (A117602).

\section{References}

Au, L., Kwong, K., Chou, J. C., Tso, A., \& Wong, M. (2009). Prevalence of overweight and obesity in Chinese American children in New York City. Journal of Immigrant Minoityr Health, 11(5), 337341.

Birch, L. L., \& Davison, K. K. (2001). Family environmental factors influencing the developing behavioral controls of food intake and childhood overweight. Pediatrics Clinical North America, 48(4), 893-907.

Boles, R. E., Nelson, T. D., Chamberlin, L. A., Valenzuela, J. M., Sherman, S. N., Johnson, S. L., et al. (2010). Confirmatory factor analysis of the Child Feeding Questionnaire among low-income African American families of preschool children. Appetite, 54(2), 402-405. 
Boutelle, K. N., Cafri, G., \& Crow, S. J. (2011). Parent-only treatment for childhood obesity: a randomized controlled trial. Obesity (Silver Spring), 19(3), 574-580.

Boutelle, K. N., Cafri, G., \& Crow, S. J. (2012). Parent predictors of child weight change in family based behavioral obesity treatment. Obesity (Silver Spring), 20(7), 1539-1543.

Bruss, M. B., Morris, J., \& Dannison, L. (2003). Prevention of childhood obesity: sociocultural and familial factors. Journal of American Dietitian Association, 103(8), 1042-1045.

Bureau, U. S. C. o. (2009). The Asian Alone Population in the United States: 2009, from http://www.census.gov/population/www/socdemo/race/api.html

Chen, J. L., \& Wu, Y. (2008). Cardiovascular Risk Factors in Chinese American Children: Associations between overweight, acculturation and physical activity Journal of Pediatric Health Care, 22, 103-110.

Chen, J. L., Kennedy, C., Yeh, C. H., \& Kools, S. (2005). Risk factors for childhood obesity in elementary school-age Taiwanese children. Progress Cardiovascular Nursing, 20(3), 96-103.

Chia, Y. (2008). Maternal labour supply and childhood obesity in Canada: Evidence from the NLSCY. Canadian Journal of Economics, 41, 217-244.

Cole, T. J., Bellizzi, M. C., Flegal, K. M., \& Dietz, W. H. (2000). Establishing a standard definition for child overweight and obesity worldwide: international survey. BMJ, 320(7244), 1240-1243.

Crawford, D., Timperio, A., Telford, A., \& Salmon, J. (2006). Parental concerns about childhood obesity and the strategies employed to prevent unhealthy weight gain in children. Public Health Nutrition, 9(7), 889-895.

De Meester, F., Van Dyck, D., De Bourdeaudhuij, I., \& Cardon, G. (2014). Parental perceived neighborhood attributes: associations with active transport and physical activity among 10-12 year old children and the mediating role of independent mobility. BMC Public Health, 14(1), 631.

Fisher, J. O., Mitchell, D. C., Smiciklas-Wright, H., \& Birch, L. L. (2002). Parental influences on young girls' fruit and vegetable, micronutrient, and fat intakes. Journal of American Dietitian Association, 102(1), 58-64.

Fitzgibbon, M. L., Stolley, M. R., Schiffer, L., Van Horn, L., KauferChristoffel, K., \& Dyer, A. (2005). Two-year follow-up results for Hip-Hop to Health Jr.: a randomized controlled trial for overweight prevention in preschool minority children. Journal of Pediatrics, 146(5), 618-625.

Fitzgibbon, M. L., Stolley, M. R., Schiffer, L., Van Horn, L., KauferChristoffel, K., \& Dyer, A. (2006). Hip-Hop to Health Jr. for Latino preschool children. Obesity (Silver Spring), 14(9), 1616-1625.

Fitzgibbon, M. L., Stolley, M. R., Schiffer, L. A., Braunschweig, C. L., Gomez, S. L., Van Horn, L., et al. (2010). Hip-Hop to Health Jr. Obesity Prevention Effectiveness Trial: Postintervention Results. Obesity (Silver Spring), 19(5), 994-1010.

Freedman, D. S., \& Perry, G. . (2000). Body composition and health status among children and adolescents. Preventive Medicine, 31, 34-53.

Golan, M., \& Weizman, A. (1998). Reliability and validity of the Family Eating and Activity Habits Questionnaire. European Journal Clinical Nutrition, 52(10), 771-777.

Harvey-Berino, J., \& Rourke, J. (2003). Obesity prevention in preschool native-american children: a pilot study using home visiting. Obesity Research, 11(5), 606-611.

Hennessy, E., Hughes, S. O., Goldberg, J. P., Hyatt, R. R., \& Economos, C. D. (2012). Permissive parental feeding behavior is associated with an increase in intake of low-nutrient-dense foods among American children living in rural communities. Journal Academy Nutrition Diet, 112(1), 142-148.

Huang, S. H., Parks, E. P., Kumanyika, S. K., Grier, S. A., Shults, J., Stallings, V. A., et al. (2012). Childfeeding practices among Chinese-American and non-Hispanic white caregivers. Appetite, 58(3), 922-927.

Karp, S. M., Barry, K. M., Gesell, S. B., Po'e, E. K., Dietrich, M. S., \& Barkin, S. L. (2014). Parental feeding patterns and child weight status for Latino preschoolers. Obesity Research Clinical Practice, 8(1), e88-97. 
Kasemsup, R., \& Reicks, M. (2006). The relationship between maternal child-feeding practices and overweight in Hmong preschool children. Ethnic Disparities, 16(1), 187-193.

Kral, T. V., \& Rauh, E. M. (2010). Eating behaviors of children in the context of their family environment. Physiological Behaviors, 100(5), 567-573.

Kroller, K., \& Warschburger, P. (2008). Associations between maternal feeding style and food intake of children with a higher risk for overweight. Appetite, 51(1), 166-172.

Liu, E., Hsiao. C., Matsumoto, T., \& Chou, S. (2009). Maternal full-time employment and overweight children: Parametric, semi-parametric, and non-parametric assessment. Journal of Economics, 152(1), 61-69.

May, A. L., Donohue, M., Scanlon, K. S., Sherry, B., Dalenius, K., Faulkner, P., et al. (2007). Childfeeding strategies are associated with maternal concern about children becoming overweight, but not children's weight status. Journal American Dietitian Association, 107(7), 1167-1175.

McGowan, L., Croker, H., Wardle, J., \& Cooke, L. J. (2012). Environmental and individual determinants of core and non-core food and drink intake in preschool-aged children in the United Kingdom. European Journal Clinical Nutrition, 66(3), 322-328.

Morrissey, T. W., Dunifon, R. E., \& Kalil, A. (2011). Maternal employment, work schedules, and children's body mass index. Child Development, 82(1), 66-81.

Oreskovic, N. M., Winickoff, J. P., Kuhlthau, K. A., Romm, D., \& Perrin, J. M. (2009). Obesity and the built environment among Massachusetts children. Clinical Pediatrics (Philadephia), 48(9), 904912.

Rich, S. S., Essery, E. V., Sanborn, C. F., DiMarco, N. M., Morales, L. K., \& LeClere, S. M. (2008). Predictors of body size stigmatization in Hispanic preschool children. Obesity (Silver Spring), 16 Suppl 2, S11-17.

Rollins, B. Y., Loken, E., Savage, J. S., \& Birch, L. L. (2014). Maternal controlling feeding practices and girls' inhibitory control interact to predict changes in BMI and eating in the absence of hunger from 5 to 7 y. American JournalClinical Nutrition, 99(2), 249-257.

Sturm, R., \& Datar, A. (2005). Body mass index in elementary school children, metropolitan area food prices and food outlet density. Public Health, 119(12), 1059-1068.

Willenberg, L. J., Ashbolt, R., Holland, D., Gibbs, L., MacDougall, C., Garrard, J., et al. (2010). Increasing school playground physical activity: a mixed methods study combining environmental measures and children's perspectives. Journalof Science Medine Sport, 13(2), 210-216.

Wrotniak, B. H., Epstein, L. H., Paluch, R. A., \& Roemmich, J. N. (2004). Parent weight change as a predictor of child weight change in family-based behavioral obesity treatment. Archieve Pediatricsc Adolescent Medicine, 158(4), 342-347.

Xu, L., Dubois, L., Burnier, D., Girard, M., \& Prud'homme, D. (2011). Parental overweight/obesity, social factors, and child overweight/obesity at 7 years of age. Pediatrics International, 53(6), 826-831.

Zhang, L., \& McIntosh, W. A. (2011). Children's weight status and maternal and paternal feeding practices. Journal Child Health Care, 15(4), 389-400.

Author Information

Corresponding Author:

*Jyu-Lin Chen, PhD, RN, CNS

Associate Professor

University of California, San Francisco

Department of Family Health Care Nursing

2 Koret Way

Box 0606

San Francisco, CA 94143

Phone- (415) 502-6015 
Fax- (415) 753-2161

Email: jyu-lin.chen@nursing.ucsf.edu

Jingxiong Jiang

National Center for Women's and Children's Health

China CDC, Beijing, China

2. jiangjingxiong@hotmail.com

Ruey-Hsia Wang

Kaohsiung Medical University

School of Nursing

Kaohsiung, Taiwan.

Email: wrhsia@kmu.edu.tw

* corresponding author 